\title{
Oral health of children in England: a call to action!
}

Jenny Godson, ${ }^{1}$ Julia Csikar,, ${ }^{1,2}$ Sandra White ${ }^{1}$

\section{THE IMPACT OF POOR ORAL HEALTH}

Oral health is part of general health and well-being and contributes to the development of a healthy child. The most common oral disease affecting young children is dental caries (figure 1), which is largely preventable and is a public health priority. Oral health is one of Public Health England's (PHE) priorities linking to; getting the best start in life, childhood obesity, nutrition including breastfeeding, weaning and cross-cutting themes such as inequalities and social justice. Poor oral health in children impacts on the children themselves and on their family and society. Dental caries is the most common reason for 5-9 year olds in England to be admitted to hospital, where they have teeth out under general anaesthesia. Over 60000 children aged 0-19 years were admitted to hospital to have teeth removed under general anaesthesia in 2015/2016. ${ }^{1}$

Children with dental caries suffer pain and infection and often have difficulties eating, sleeping and socialising. ${ }^{2}$ They have to take time off school to attend the dentist and hospital, and this is often their first introduction to dental care and can lead to fear and anxiety with lifetime consequences. Poor oral health may be a sentinel marker of wider health and social issues, and dental neglect may be part of a safeguarding issue. ${ }^{3}$ Dental care is a significant cost with the National Health Service (NHS) spending $£ 3.4$ billion on all age dental care and an estimated additional $£ 2.3$ billion in the private dental market. ${ }^{4}$

\section{ORAL HEALTH OF YOUNG CHILDREN IN ENGLAND}

The National Dental Epidemiology Programme gives support for the ongoing gathering, analysing and disseminating of robust and reliable information of the oral health needs of local populations. ${ }^{5}$ Although the oral health of 5 year olds in England and across the UK is improving

${ }^{1}$ Dental Public Health, Public Health England, London, UK

${ }^{2}$ Dental Public Health, The University of Leeds, Leeds, UK

Correspondence to Dr Jenny Godson, Blenheim House, West One, Leeds LS1 4PL, UK: Jenny.Godson@phe.gov.uk region 2015.

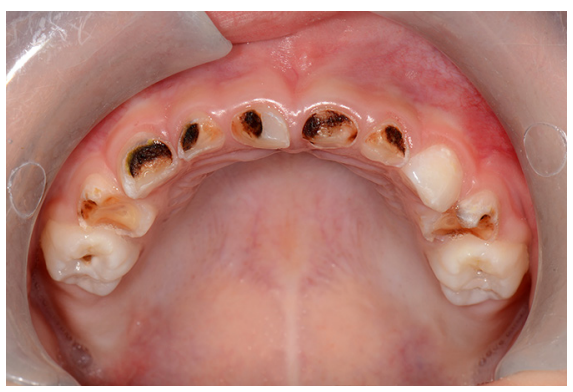

Figure 1 Dental caries in the deciduous dentition. (figure 2), the most recent 5-year-old dental survey ${ }^{6}$ found that almost a quarter (24.7\%) will start school with dental caries and for those with decay they will have 3-4 teeth affected. Dental caries starts early in life; the first survey of 3 year olds published in $2014^{7}$ found that $12 \%$ had experience of dental caries with on average three teeth affected. There are significant variations in oral health across English regions figure 3 with 33\% of 5-year-old children in the North West experiencing dental caries compared with 20\% in the South East of England. However, examined at a local authority level, the differences are even greater. Within the North West region, $56 \%$ of 5 year olds in Blackburn and Darwen had dental caries, more than double the national average, while in Cheshire West and Chester, this figure is $20 \%$, well below the national average. ${ }^{6}$

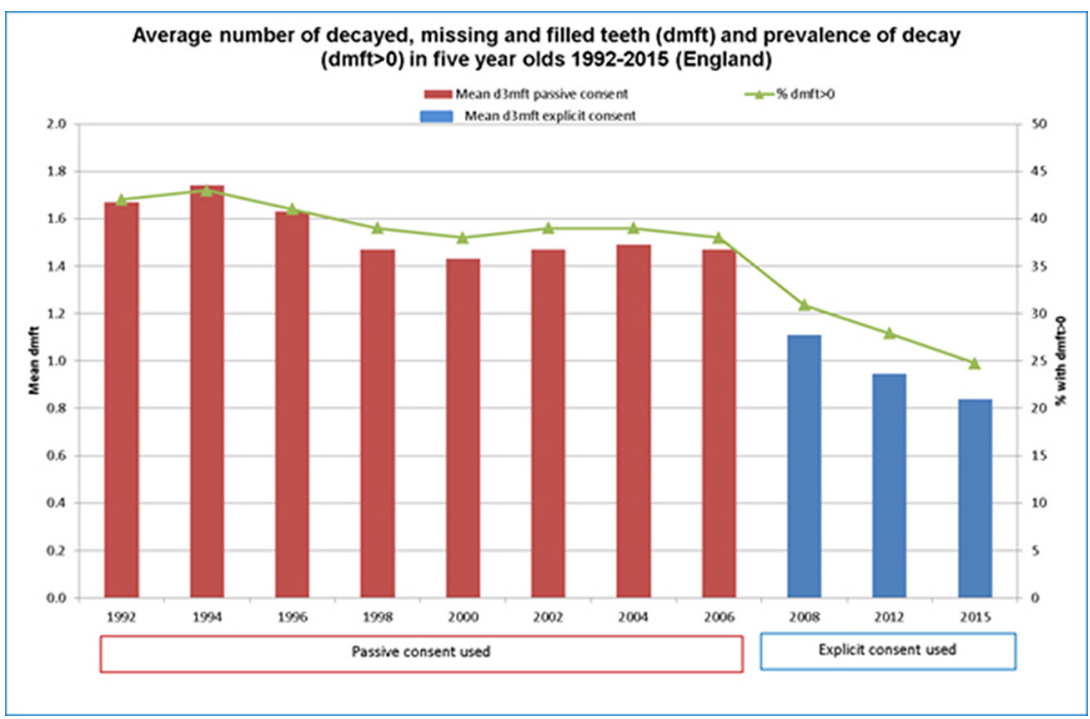

Figure 2 Source: Public Health England dental epidemiology programme

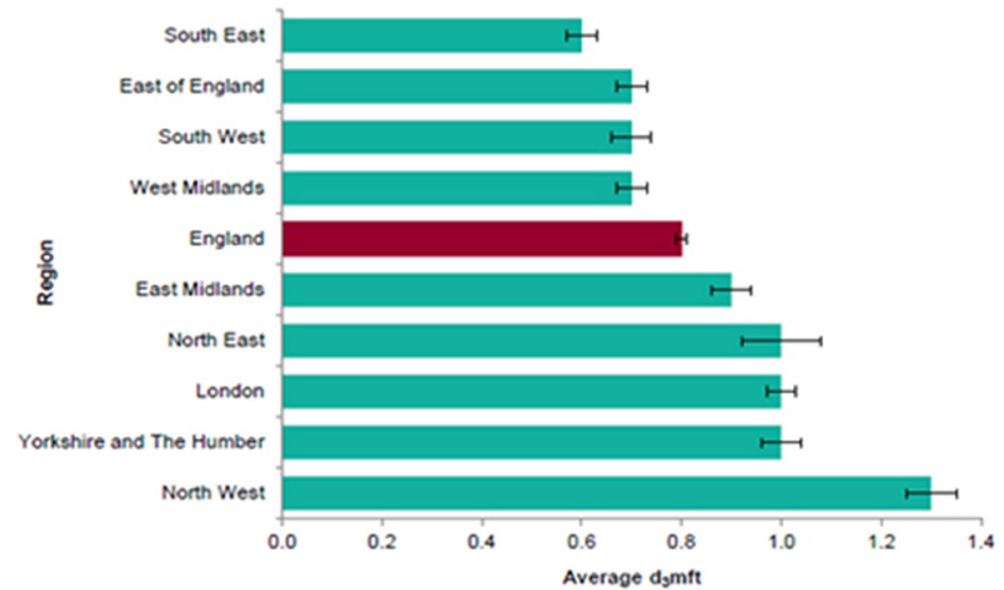

Figure 3 Results of national dental epidemiology programme dental surveys of 5 year olds in 2015. Average number of decayed, missing and filled teeth (dmft) among 5 year olds in England by 


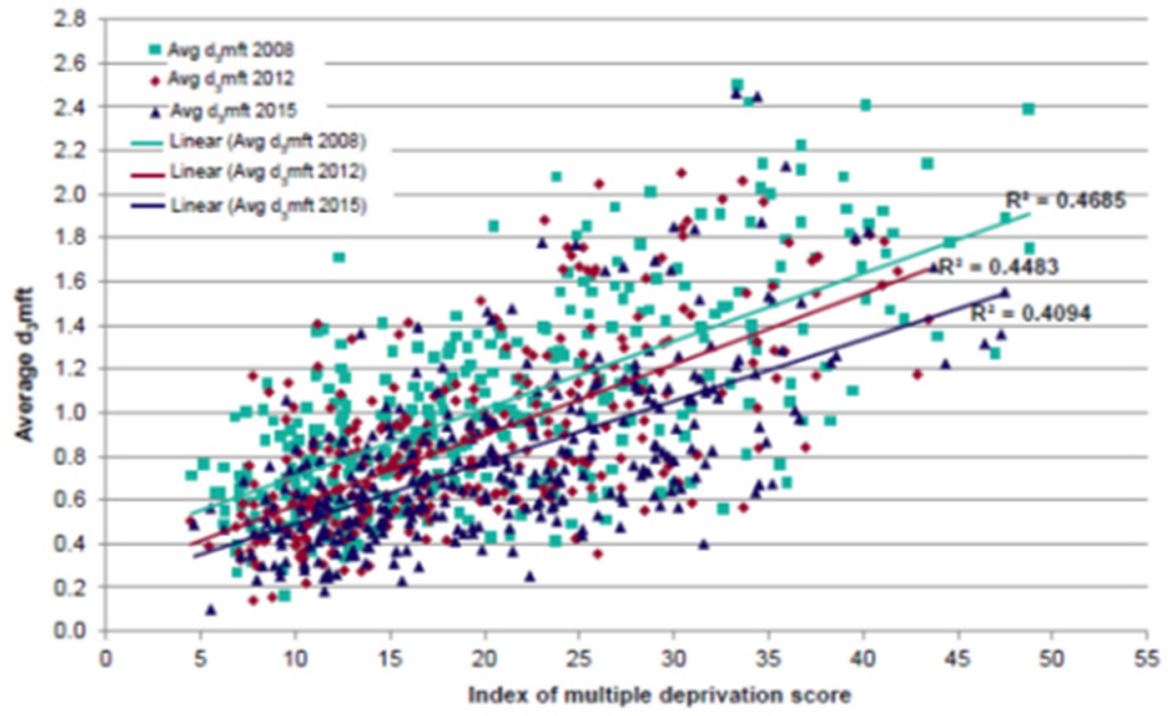

Figure 4 Correlation between numbers of decayed, missing and filled teeth ( $\mathrm{dmft}$ ) and index of multiple deprivation score for lower tier local authorities in England (2008, 2012 and 2015).

Stark inequalities exist with some of the most vulnerable, disadvantaged and socially excluded facing significant oral health problems. Almost $41 \%$ of this variation can be explained by material deprivation (figure 4) with regard to the most recent data for 5 year olds, ${ }^{6}$ while inequalities were also found according to ethnicity with $51 \%$ of Chinese 5 year olds having obvious decay, followed by $48 \%$ of Eastern European with the remaining groups, ranging from $45 \%$ to $21 \%$ (figure 5).

With regard to 5 year old children attending special support schools, 22\% had experienced dental caries with on average four teeth affected. ${ }^{8}$ In comparison with their mainstream educated peers the prevalence and severity were

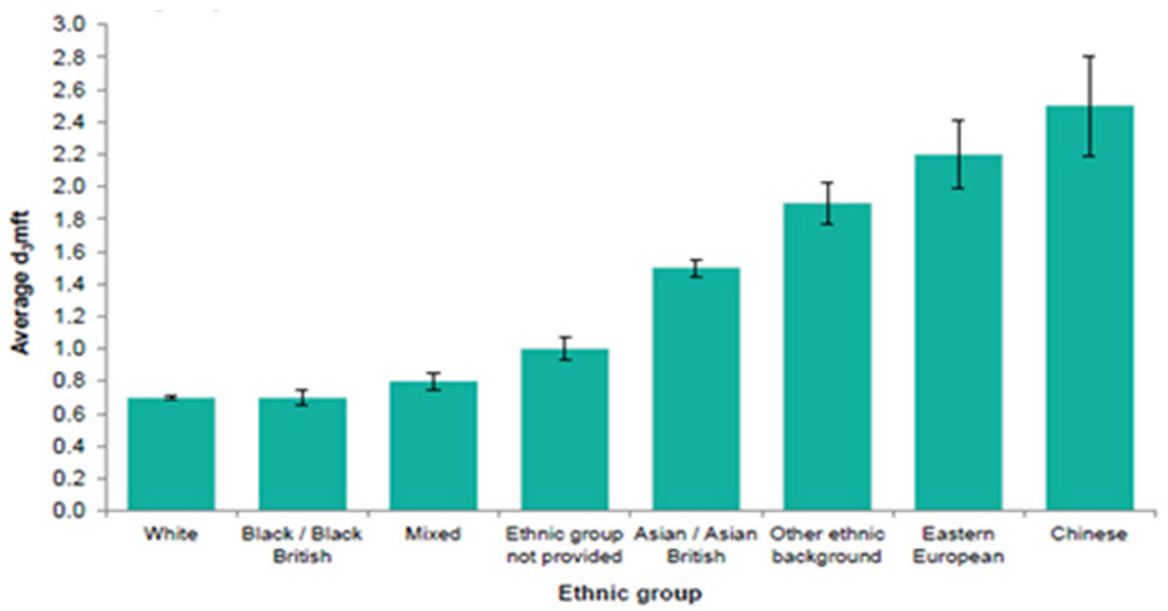

Figure 5 Results of national dental epidemiology programme dental surveys of 5 year olds in 2015. Average number of decayed, missing and filled teeth ( $\mathrm{dmft}$ ) among 5 year olds in England by ethnic group 2015. only slightly lower for children attending special support schools; however, they have more teeth affected on average and were twice as likely to have had one or more teeth extracted. ${ }^{8}$

\section{WHAT CAN WE DO TO IMPROVE ORAL HEALTH AND ADDRESS ORAL HEALTH INEQUALITIES?}

Dental caries is caused by multi-factorial and complex interactions. Cariogenic bacteria in the mouth metabolise dietary carbohydrates producing acid by products that can demineralise teeth. ${ }^{9}$ The buffering action of saliva can change the process to remineralisation, which is more rapid in the presence of fluoride. ${ }^{10}$
WHAT WORKS AT AN INDIVIDUAL PATIENT LEVEL?

At an individual level, we have good evidence of what works to improve oral health and prevent dental caries. Delivering Better Oral Health: an evidence based toolkit for prevention (third edition) outlines the current preventive advice and treatment that improves oral health at an individual level. ${ }^{11}$ Since the publication of the first edition, which stated that toothpaste with less than 1000 parts per million (ppm) fluoride was not effective in preventing dental caries, manufacturers have reformulated their products, with few now having less than $1000 \mathrm{ppm}$ fluoride. In Delivering Better Oral Health (DBOH), advice to prevent dental caries for children is given for 0-3 year olds, 3-6year olds and 0-6year olds at high risk of dental caries and are summarised in box 1. Top tips for health and social care professionals have also been developed based on the key evidence-based actions in $\mathrm{DBOH}^{12}$

The National Institute for Health and Care Excellence (NICE) in their recent guidance 'Oral Health Promotion: General Dental Practice ${ }^{14}$ supports the messages within $\mathrm{DBOH}$ and describes how dental practice teams can give such advice to support behaviour change.

\section{WHAT WORKS FOR POPULATIONS?}

Evidence of what works for oral health improvement at a population level has been reviewed by NICE $^{15}$ and PHE. ${ }^{16}$ The latter outlined nine population interventions that have evidence that they improve oral health:

- Oral health training for the wider professional workforce

- Integration of oral health into targeted home visits by health/socialcare workers

- Targeted community-based fluoride varnish programmes

- Targeted provision of toothbrushes and fluoride tooth paste (ie, postal or through health visitors)

- Supervised tooth brushing with fluoride toothpaste in targeted childhood settings

- Healthy food and drink policies in childhood settings

- Fluoridation of the public water supplies

- Targeted peer (lay) support groups/ peer oral health workers

- Influencing local and national government policies.

In England, The Health and Social Care Act (2012) conferred statutory responsibilities $^{17}$ on local authorities to provide 
Box 1 Evidence-based advice to prevent dental caries from Delivering Better Oral Health's (third edition) $)^{13}$

\section{Brushing children's teeth}

- Start brushing as soon as the first tooth appears (usually at about 6 months of age), at least twice a day with fluoride toothpaste last thing at night and on at least one other occasion.

- Brushing at bedtime is important as it makes sure that the fluoride continues to protect the teeth while your child is asleep.

- Parents/carers should brush or help their child to brush their teeth until they are at least 7 years old to make sure the teeth are cleaned properly, to supervise the amount of toothpaste used and to prevent licking or eating the toothpaste.

- For the maximum prevention of dental caries for children aged 0-6years, use toothpastes containing 1350-1500 parts per million fluoride.

- 0-3year olds use a smear and for 3-6year olds a pea-sized amount (see figure 7).

\section{Reducing consumption of free sugars}

- Reduce the amount and frequency of having foods and drinks that contain sugar; only give sweet foods including dried fruit at meal times.

- Squashes sweetened with sugar, fizzy drinks, soft drinks and juice drinks have no place in a child's daily diet.

- Limit the amount of fruit juice and/or smoothies your child drinks to a maximum of $150 \mathrm{ml}$ (one portion) in total per day and drink it with meals to reduce the risk of dental caries.

- Always ask for sugar-free medicines.

\section{For babies}

- Breast milk is the only food or drink babies need for around the first 6 months of their life. Formula milk is the only suitable alternative to breast milk.

- From the age of 6 months, bottle-fed babies should be introduced to drinking from a free-flow cup. Bottle feeding should be discouraged from 12 months old.

- Only breast or formula milk or cooled, boiled water should be given in bottles.

- Only milk or water should be drunk between meals and avoid adding sugar to foods or drinks for your baby.

\section{Visiting the dentist}

- Take your child to see the dentist as soon as their teeth start to appear and visit regularly, as often as your dentist recommends.

- Ask your dentist about fluoride varnish—all children over 3 years should have this applied to their teeth. If younger children are at particular risk of dental caries, the dentist may apply to their teeth.

- National Health Service dental treatment is free for children under 18 or under 19 and in qualifying full-time education.

- Women are entitled to free National Health Service dental treatment during pregnancy and any treatment commenced before their child's first birthday.

or commission oral health programmes to meet the needs of their local population and duties and powers with regard to water fluoridation. ${ }^{18}$ In the devolved nations, a national approach has been adopted, with programmes such as 'Childsmile' in Scotland ${ }^{19} 20$ and 'Designed to Smile' in Wales ${ }^{21}$ commissioned to address poor oral health. Learning from these successful approaches has resulted in many of the elements of these programmes being currently commissioned by local authorities in England, who have the statutory responsibility for oral health improvement. ${ }^{22}$ However, it is clear that if we are to succeed, action to reduce the consumption of free sugars and increase access to fluoride is required across the health and social care system. Oral health improvement needs to be everyone's business.

\section{Child oral health improvement} programme board

In September 2016, PHE launched the Children's Oral Health Improvement Programme Board to develop partnerships and mutual support and coordinate action across the system. Board members represent organisations across the health, education, voluntary and community sector with the shared ambition that 'every child should grow up free from tooth decay' as part of getting the best start in life. In order to achieve this ambition, the board partners aim to improve the oral health of all children and reduce the oral health gap for disadvantaged children. The Board has a cross-organisational action plan that outlines five high-level objectives, with examples of how they will be delivered and what success will look like in $2020 .^{23}$ Since the Board's launch, partners have delivered or are on track to deliver commitments including publishing tools and resources to support delivery of the ambition.

\section{Policy and oral health improvement}

National and local government policy have a key role to play, and the recent government action to address childhood obesity will also impact on oral health as both share the common risk factor-consumption of free sugars. In 2015, the Scientific Advisory Committee on Nutrition $(\mathrm{SACN})^{24}$ recommended that the intake of free sugars should not exceed 5\% of total daily energy intake for all age groups. SACN concluded that increasing the proportion of calories consumed as sugar increases the likelihood of a higher overall energy intake, thereby increasing the risk of weight gain and dental caries. PHE's report Sugar reduction: the evidence for action $^{25}$ was published in October 2015. It considered the evidence on various drivers of sugar intake and based on the analyses conducted identified eight areas of action that, if implemented together, could change consumption patterns. Two of these have already been taken forward; reformulation of a monitored programme of gradual sugar reduction in everyday food and drink and the sugar levy. All sectors of the food industry will be challenged to reduce the overall sugar content of all food products consumed by children by around $20 \%$ over the next 4 years (by 2020), including an initial 5\% reduction in the first year (by August 2017). The initial focus will be on those products that contribute most to children's sugar intakes, which are captured within the following categories: breakfast cereals, chocolate confectionery, sweet confectionery, yoghourt and fromage frais, ice cream, sweet spreads and sauces, cakes, morning goods (eg, pastries, croissants, etc), puddings and biscuits. The government announced in the budget statement that companies making soft drinks should pay a levy on drinks with added sugar starting from April 2018. The levy will apply to any drink with total sugar content exceeding $5 \mathrm{~g}$ per $100 \mathrm{~mL}$ and the levy will increase for drinks with $8 \mathrm{~g}$ or more 
per $100 \mathrm{~mL}$. The levy will be legislated in the Finance Bill in 2017.

\section{Water fluoridation}

Reviews of research undertaken worldwide have shown that water fluoridation is a safe and effective public health intervention that should be considered in areas where dental caries levels are high. ${ }^{26}$ This intervention does not rely on individual behaviour change. All water supplies contain some naturally occurring fluoride, the optimal concentration level is $1 \mathrm{ppm}$ or $1 \mathrm{mg}$ of fluoride per litre of water. ${ }^{27}$ This concentration level reduces the likelihood of developing dental caries and also minimises the severity of the disease. Water fluoridation schemes are designed to supplement naturally occurring fluoride levels to $1 \mathrm{ppm}$ to provide dental health benefits. Currently, in the UK, approximately $10 \%$ of the population drink fluoridated water in comparison with $70 \%$ of the population in the USA and in Australia. Across England, existing fluoridation schemes have been in operation for over 40 years, Birmingham is the oldest, which has been running for 50 years. $^{28}$ Across England, 6 million people in England access a water supply that is fluoridated and another third of a million people access water that naturally contains fluoride at the optimal level. ${ }^{27}$

A recently published water fluoridation health monitoring report found that children aged 5 years living in fluoridated areas were less likely to have dental caries (15\%) compared with children in non-fluoridated areas $(28 \%)$ even when deprivation and ethnicity were considered. ${ }^{27}$ In addition, there are lower rates of child dental admissions to hospital for tooth extractions in fluoridated than non-fluoridated areas $(45 \%$ fewer hospital admissions of children aged 1-4 for dental caries). ${ }^{28}$

The water fluoridation debate usually focuses on several issues: the dental health need within the community affected, if a scheme could be an effective measure to reduce dental caries, if fluoridation is safe (not causing harm to health), who will benefit from such an intervention, if people actually want it, ethical issues and whether it is cost-effective. ${ }^{27}$

\section{Healthy settings}

The development of healthy settings and healthy food policies are oral
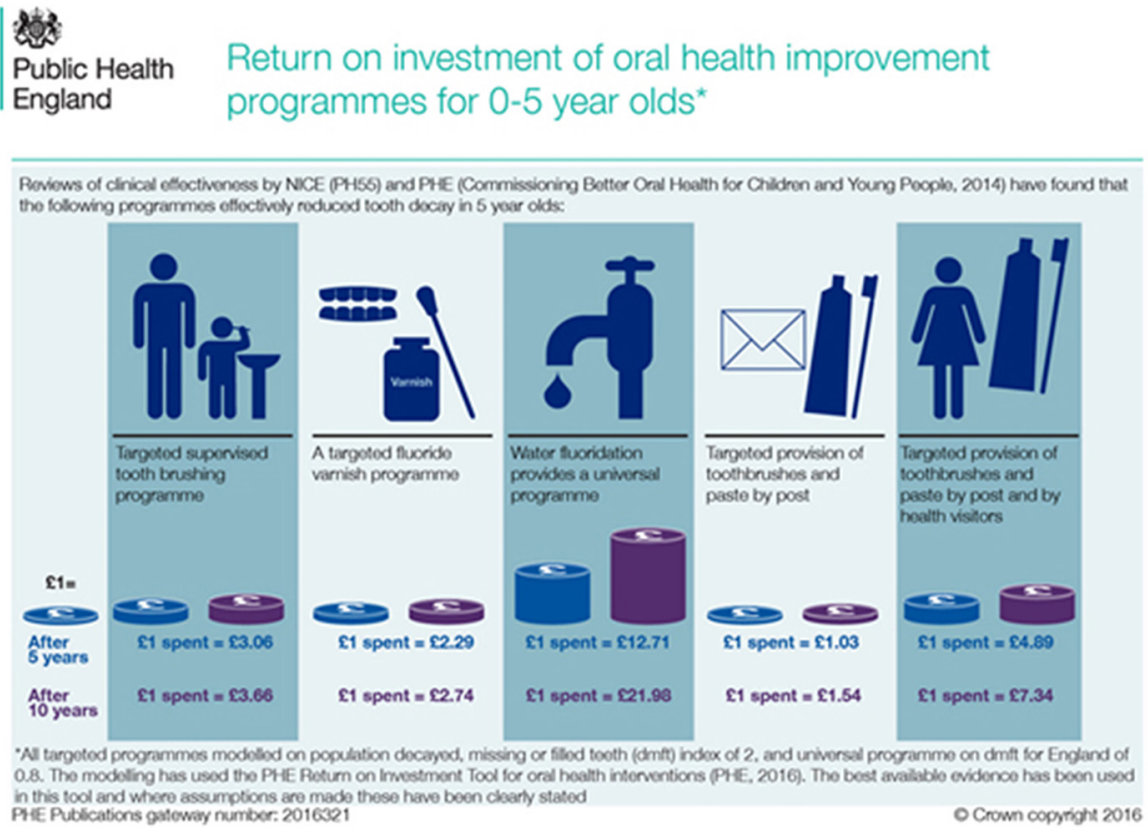

Figure 6 Infographic modelling the return on investment of oral health programmes. PHE, Public Health England (2016).

health promoting. Many targeted early-years settings are running daily supervised tooth brushing with fluoride toothpaste and/or fluoride varnish programmes, which have good evidence of reducing dental caries in 5 year olds. In addition, local authorities include oral health in their commissioning of services for $0-19$ year olds. Oral health has been included in the delivery of the Healthy Child Programme (HCP) at the mandated contact points and especially around the time when the first tooth (6 months of age) erupts to encourage the commencement of tooth brushing twice a day with a smear of family toothpaste. The e-learning resource supporting the delivery of oral health within HCP has

just been updated in collaboration with the Royal College of Paediatrics and Child Health and is freely available: http://www.rcpch.ac.uk/e-learning.

\section{Cost effectiveness and return on investment}

As local authorities come under increasing financial pressure, information regarding the cost effectiveness of oral health improvement programmes becomes essential to inform business plans and the case for investment. A rapid review of the evidence of the cost-effectiveness of interventions to improve the oral health of 5 year olds ${ }^{29}$ and a bespoke return on

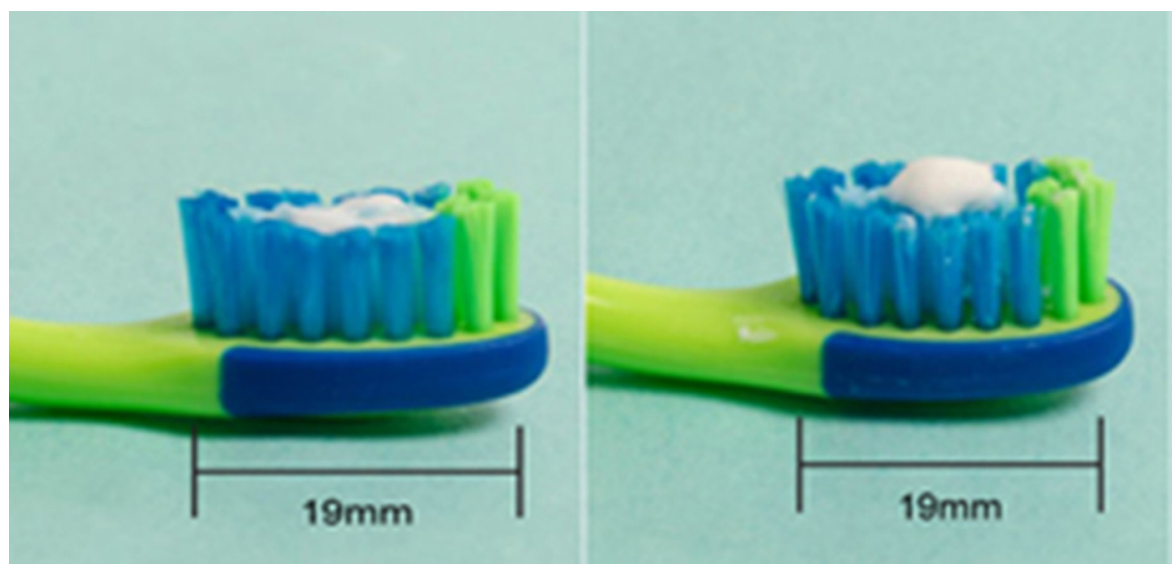

Figure 7 Ilustration of a smear (for 0-3 year olds) and pea-size (for 3-6 year olds) amount of toothpaste. 
investment (ROI) tool were commissioned from the York Health Economics Consortium. ${ }^{30}$ This provided an update to the economic evidence review on oral health prevention measures published by NICE in 2014. ${ }^{31} 32$ It specifically examined the cost-effectiveness of those oral health interventions with good evidence of effectiveness in reducing the average number of decayed, missing and filled teeth in 5 year olds. This is the indicator that is included in both the NHS ${ }^{33}$ and Public Health Outcomes frameworks. ${ }^{34}$ The interventions included were supervised tooth brushing, application of fluoride varnish, water fluoridation, provision of toothbrushes and paste and interventions provided in home visits by health workers. The review concluded that they found few studies that added to the cost-effectiveness evidence base established by $\mathrm{NICE}^{15}$ for these interventions that were generalisable to England. However, the ROI tool allows the effectiveness data to estimate the reduction in dental caries as a result of the intervention, the costs of delivering each of the programmes and the cost savings. These savings areto the NHS, (which includes treatment costs in primary and secondary care), and to wider society (which is estimated for the child and parent/carer as days lost at school and work).

Using modelling data, the ROI tool has been used to calculate the ROI of these five oral health improvement programmes at 5 and 10 years (figure 6).

\section{What can we do? A call to action}

Paediatricians and the wider healthcare and early-years workforce have key roles in making every contact count: having the knowledge of the key evidence-based messages to support families to take action for oral health improvement ${ }^{13}$ and the skills to support behaviour change and, when needed, signposting to local dental services if dental treatment or further support is required. Paediatricians have a key role as advocates for oral health improvement, at an individual patient level and in their wider work influencing the system to adopt oral-health-promoting initiatives, for example, healthy eating policies, supporting healthy settings and wider population programmes that work. We can all share the ambition that every child should grow up free from tooth decay, dental caries is preventable, we know what works and we can demonstrate improvement.

Contributors All authors have equally contributed to this manuscript.

Competing interests None declared.

Patient consent Obtained.

Provenance and peer review Commissioned: externally peer reviewed.

(C) Article author(s) (or their employer(s) unless otherwise stated in the text of the article) 2018. All rights reserved. No commercial use is permitted unless otherwise expressly granted.

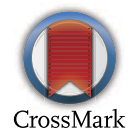

To cite Godson J, Csikar J, White S. Arch Dis Child 2018;103:5-10.

Received 3 April 2017

Revised 3 August 2017

Accepted 8 August 2017

Published Online First 12 October 2017

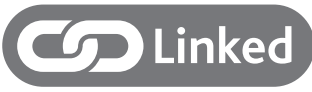

- http://dx.doi.org/10.1136/archdischild-2017313892

Arch Dis Child 2018;103:5-10.

doi:10.1136/archdischild-2017-312725

\section{REFERENCES}

1 Health and Social Care Information Centre. Hospital Episode Statistics, Admitted Patient Care,2013-14. England, 2015. http://content.digital.nhs.uk/catalogue/ PUB16719/hosp-epis-stat-admi-diag-2013-14-tab.xlsx (accessed 06 Feb 2017).

2 Nuttall N, Harker R. Impact of oral health. Children's dental health in the United Kingdom 2003. London: The Stationery Office, 2004.

3 Harris JC, Balmer RC, Sidebotham PD. British Society of Paediatric Dentistry: a policy document on dental neglect in children. Int J Paediatr Dent 2009 (Epub ahead of print: 14 May 2009).

4 NHS England. Improving dental care and oral Health a call for action, 2014

5 PublicHealth England 2017. Dental Public Health Intelligence Programme. http://www.nwph.net/ dentalhealth/ (accessed 31 Aug 2017).

6 Public Health England. National Dental Epidemiology Programme for England: oral health survey of fiveyear-old children 2015. A report on the prevalence and severity of dental decay, 2016. http://www. nwph.net/dentalhealth/14_15_5yearold/14_15_16/ DPHEP\%20for\%20England\%200H\%20Survey\% 205yr\%202015\%20Report\%20FINAL\%20Gateway\% 20approved.pdf

7 Public Health England. National Dental Epidemiology Programme for England: oral health survey of threeyear-old children 2013, 2013. http://www.nwph.net/ dentalhealth/reports/DPHEP\%20for\%20England\% $200 \mathrm{H} \% 20$ Survey\%203yr\%202013\%20Report.pdf (accessed 30 Aug 2017).

8 Public Health England. National Dental Epidemiology Programme for England: oral health survey of fiveyear-old and 12-year-old children attending special support schools 2014, 2015. http://www.nwph.net/ dentalhealth/specsurvey/Protocol\%202013_14\% 20 Special\%20Support $\% 20$ Schools $\% 20$ version $\%$ 202.pdf
9 Marsh P, Martin M. Oral Microbiology. 4th edn. Oxford: Wright, 1999.

10 Selwitz RH, Ismail Al, Pitts NB, et al. Dental caries. The Lancet 2007:369:51-9.

11 Public Health England. Delivering better oral health: an evidence-based toolkit for prevention. Third edn. London: Public Health England, 2014. https:// www.gov.uk/government/uploads/system/uploads/ attachment_data/file/605266/Delivering_better_oral_ health.pdf

12 Public Health England. Improving oral health for children and young people for health visitors, school nurses and practice nurses, 2016. https://vivbennett. blog.gov.uk/2016/09/27/oral-health-health-visitorsand-school-nurses/

13 Public Health England. Delivering better oral health: a quick guide to a healthy mouth in children. London, 2017. https://www.gov.uk/government/ uploads/system/uploads/attachment_data/file/ 601834/healthy_mouth_children_quick_ guide.pdf

14 National Institute for Health and Care Excellence. Oral health promotion: general dental practice. London: National Institute for Health and Care Excellence, 2015. https://www.nice.org.uk/ guidance/ng30

15 National Institute for Health and Care Excellence. Oral health: local authority oral health improvement strategies. London, 2014. https://www.nice.org.uk/ guidance/ph55

16 Public Health England. Commissioning better oral health. London, 2014. https://www.gov.uk/go vernment/uploads/system/uploads/attachment_data/ file/321503/CBOHMaindocumentJUNE2014.pdf

17 Logislation.gov.uk. Health and Social Care Act, 2012.

18 Gov.UK. Water Fluoridation (Proposals and Consultation) (England) Regulations 2013: impact assessment. Department of Health, 2013.

19 Macpherson LM, Ball GE, Brewster L, et al. Childsmile: the national child oral health improvement programme in Scotland. Part 1: establishment and development. $\mathrm{Br}$ Dent J 2010;209:73-8.

20 Turner S, Brewster L, Kidd J, et al. Childsmile: the national child oral health improvement programme in Scotland. Part 2: Monitoring and delivery. Br Dent J 2010;209:79-83

21 Trubey R, Chestnutt I. 2010. Designed to Smile. Evaluation of a national child oral health improvement programme. Interim Report II. Dental Public Health Unit, Cardiff University School of Dentistry. http:// www.designedtosmile.co.uk/D2S\%20Part\%2011\% 20Evaluation $\% 20$ Interim\%20Report $\% 2011 \% 20-\%$ 20December\%202013.pdf

22 NHS Bodies and Local Authorities: Partnership Arrangements, Care Trusts, Public Health and Local Healthwatch, in Regulations Statutory Instrument SI3094, 2012

23 Public Health England. Children's Oral Health Improvement Programme Board Action Plan 2016 2020, 2016.

24 Scientific Advisory Committee on Nutrition. Carbohydrates and Health. London, 2015. https:// www.gov.uk/government/uploads/system/uploads/ attachment_data/file/445503/SACN_Carbohydrates and Health.pdf

25 Public Health England. Sugar reduction: from evidence into action. 2015 https://www.gov.uk/government/ publications/sugar-reduction-from-evidence-intoaction (accessed 27 Mar 2017).

26 McDonagh MS, Whiting PF, Wilson PM, et al. Systematic review of water fluoridation. BMJ 2000;321:855-9.

27 Improving oral health: a community water fluoridation toolkit for local authorities. London: Nuffield foundation, 2016. https://www.gov.uk/government/ publications/improving-oral-health-community-waterfluoridation-toolkit 


\section{Leading article}

28 Public Health England. 2014. https://www.gov.uk/ government/publications/water-fluoridation-healthmonitoring-report-for-england-2014

29 Public Health England. A rapid review of evidence on the cost-effectiveness of interventions to improve the oral health of children aged 0-5 years, 2016. https:// www.gov.uk/government/uploads/system/uploads/ attachment_data/file/560972/Rapid_review_ROI_ oral_health_5_year_old.pdf

30 Public Health England. Return on Investment of Oral Health Interventions Tool, 2016. https://www.gov.uk/ government/publications/improving-the-oral-health-ofchildren-cost-effective-commissioning

31 Lord J, Longworth L, Singh J, et al. Oral Health GuidanceEconomic analysis of oral health promotion approaches for dental teams, 2015. https://www.nice.org.uk/ guidance/ng30/documents/oral-health-promotionapproaches-for-dental-teams-health-economic-analysis2

32 Public Health Advisory Committee. Economic Analysis of Oral Health Improvement Programmes and Interventions, 2014. https://www.nice.org.uk/ guidance/ph55/documents/economic-modelling- rx058-economic-analysis-of-oral-health-improvementprogrammes-and-interventions4

33 Department of Health. NHS Outcomes Framework 2016 to 2017. London, 2016. https://www.gov.uk/ government/publications/nhs-outcomes-framework2016-to-2017

34 Department of Health. The Public Health Outcomes Framework 2013/16. London, 2013. https://www. gov.uk/government/publications/healthy-liveshealthy-people-improving-outcomes-and-supporting transparency 